\title{
Implementasi Google Speech Untuk Penentuan Level Pembelajaran Iqro’ Berbasis Android
}

\author{
M. Fangqi Arifin ${ }^{1}$, Fitri Marisa ${ }^{2}$, Indra Dharma Wijaya ${ }^{3}$
}

\begin{abstract}
Today the rapidly evolving technological developments have prompted some people to innovate in creating various inventions to facilitate human activity itself, including in the field of pembelajaran.Salah one such innovation is the use of technology-based speech google android as a learning medium Heinich quoted interaktif.Menurut by Azhar Arsyad (2011: 4), instructional media are middlemen who bring the message or information aimed at containing instructional or teaching intentions between source and receiver. Voice / Speech recognition is a development of techniques and systems that enable the computer to accept input in the form of words which diucapkan.Android studio is an IDE for Google Android Development introduced at the Google I / 0 2013.Android Studio is an Eclipse pengembangkan of IDE.Android Studio an official IDE for Android application development.
\end{abstract}

Keywords: instructional media, Iqro ', speech recognition, android studio, google speech
Intisari--Dewasa ini perkembangan teknologi yang berkembang pesat telah mendorong sebagian manusia untuk berinovasi dalam menciptakan berbagai penemuan untuk memudahkan aktivitas manusia itu sendiri termasuk dalam bidang pembelajaran.Salah satu inovasi tersebut adalah menggunakan teknologi google speech berbasis android sebagai sebagai media pembelajaran yang interaktif.Menurut Heinich yang dikutip oleh Azhar Arsyad (2011:4), media pembelajaran adalah perantara yang membawa pesan atau informasi bertujuan instruksional atau mengandung maksud- maksud pengajaran antara sumber dan penerima. Voice/Speech recognition adalah suatu pengembangan teknik dan system yang memungkinkan computer untuk menerima masukan berupa kata yang diucapkan.Android studio adalah sebuah IDE untuk Android Development yang diperkenalkan google pada acara Google I/O 2013.Android Studio merupakan pengembangkan dari Eclipse IDE.Android Studio merupakan IDE resmi untuk pengembangan aplikasi Android.

Kata kunci :media pembelajaran,iqro',speech recognition,android studio,google speech

\section{PENDAHULUAN}

\section{A. Latar Belakang}

Al-Qur'anul karim adalah kitab suci yang menjadi pedoman hidup bagi seluruh umat islam yang diturunkan kepada Rasulullah SAW untuk seluruh umat manusia. Didalam Al-Quran juga diterangkan tentang ajaran-ajaran yang mengajak manusia agar selamat didunia dan akhirat karena tujuan diturunkannya alquran sendiri merupakan petunjuk bagi seluruh umat manusia dan tidak sedikitpun

\footnotetext{
${ }^{1}$ Status penulis, M. Fangqi Arifin Teknik Informatika Universitas Widyagama Jl. Borobudur Indah No.3 Malang, 65128 Telp (0341)492282,496919 FAX 0341-496919 fangkiarifin277@gmail.com)
} 
keraguan didalamnya. Hal ini dijelaskan dalam firman Allah SWT :

Artinya :Kitab (Al-Qur'an) ini tidak ada keraguan pada nya dan petunjuk bagi orang yang bertakwa (QS. Al-baqaroh:2)

Untuk itu diperlukan peran yang aktif dari beberapa pihak untuk memberikan pelajaran membaca Al-Quran sejak usia dini.Salah satu inovasi tersebut adalah menggunakan teknologi komputer sebagai sebagai media pembelajaran yang interaktif. Menurut Heinich yang dikutip oleh Azhar Arsyad (2011:4), media pembelajaran adalah perantara yang membawa pesan atau informasi bertujuan instruksional atau mengandung maksud- maksud pengajaran antara sumber dan penerima. Media pembelajaran itu sendiri juga bisa dibagi menjadi dua jenis, yaitu : media visual dan media cetak.

Dari latar belakang yang telah dikemukakan didapatkan masalah berikut ,

bagaimana merancang dan membangun aplikasi pembelajaran IQRO berbasis android ?

Adapun batasan masalah dalam penelitian ini adalah sebagai berikut :

- Materi yang diajarkan diambil dari buku iqro' 1-3

- Aplikasi ini berbasis android dan diaplikasikan pada android versi 4 keatas.

- Pengolahan suara menggunakan google speech

\section{LANDASAN TEORI}

\section{A. Media Pembelajaran}

Media pembelajaran adalah sarana penyampaian pesan pembelajaran kaitannya dengan model pembelajaran langsung yaitu dengan cara guru berperan sebagai penyampai informasi dan dalam hal ini guru seyogyanya menggunakan berbagai media yang sesuai.

\section{B. Iqro'}

Metode iqro' adalah suatu metode membaca Al-Qur'an yang menekankan langsung pada latihan membaca.Adapun buku panduan iqro' terdiri dari enam jilid dimulai dari tingkat yang sederhana, tahap demi tahap sampai pada tingkatan yang sempurna.Metode iqro' ini dalam prakteknya tidak membutuhkan alat yang bermacam-macam, karena ditekankan pada bacaannya (membaca huruf Al-Qur'an dengan fasih).Bacaan langsung tanpa dieja. Artinya diperkenalkan nama-nama huruf hijaiyah dengan cara belajar siswa aktif (CBSA) dan lebih bersifat individual (Zuliana, 2007).

C. Android

Android adalah sistem operasi berbasis Linux yang dipergunakan sebagai pengelola sumber daya perangkat keras, baik untuk ponsel, smartphone dan juga PC tablet. Secara umum Android adalah platform yang terbuka (Open Source) bagi para pengembang untuk menciptakan aplikasi mereka sendiri untuk digunakan oleh berbagai piranti bergerak (Ikhwan dan Hakiky, 2011)

\section{Speech Recognition}

Voice/Speech recognition adalah suatu pengembangan teknik dan system yang memungkinkan computer untuk menerima masukan berupa kata yang diucapkan.Teknologi ini memungkinkan suatu perangkat untuk mengenali dan memahami kata-kata yang diucapkan dengan cara digitalisasi kata dan mencocokkan sinyal digital tersebut dengan suatu pola tertentu yang tersimpan dalam suatu perangkat.Katakata ynag diucapkan diubah bentuknya menjadi sinyal digital dengan cara mengubah gelombang suara menjadi sekumpulan angka yang kemudian disesuaikan dengan kode-kode tertentu untuk mengidentifikasi kata-kata tersebut.

\section{ANALISIS DAN PERANCANGAN SISTEM}

\section{A. Cara Kerja Sistem}

Dari suara diproses oleh google speech untuk dapat dikenali dan dikonversikan menjadi text. Proses selanjutnya diklasifikasi oleh sistem yang sudah dibangun di aplikasi android untuk dijadikan sebuah standar penilaian apakah layak ke level selanjutnya atau tetap bertahan. 


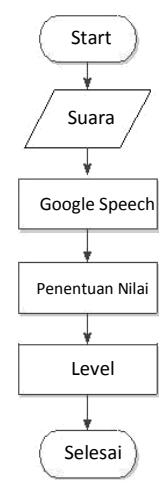

Gambar 1. Kerangka sulusi penelitian

\section{B. Use Case Diagram}

Struktur menu pada penentuan level pembelajaran iqro' pada platform android. Diagram use case mendeskripsikan sebuah interaksi antara satu atau lebih aktor dengan sistem yang akan dibuat (Munawar, 2005) .

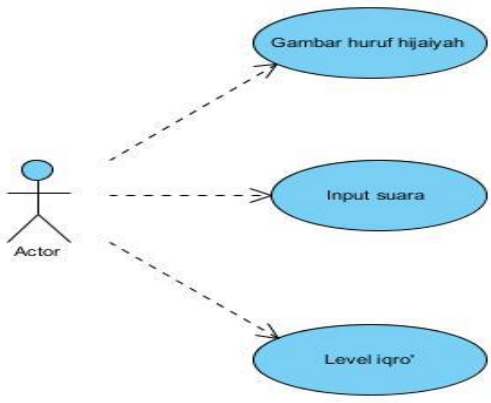

Gambar 2.Use Case Diagram

\section{Activity Diagram}

Activity diagram adalah tipe khusus dari diagram state yang memperlihatkan aliran dari suatu aktifitas ke aktifitas lainnya dalam suatu sistem. Diagram ini terutama penting dalam pemodelan fungsifungsi dalam suatu sistem dan memberi tekanan pada aliran kendali antar objek.

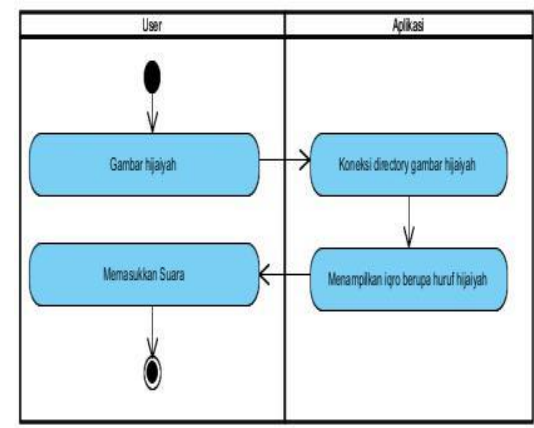

Gambar 3. Activity diagramGambar Hijaiyah user menekan tombol gambar hijaiyah. Reaksi aplikasi menyiapkan content gambar hijaiyah. Selanjutnya user dapat memasukkan suara sesuai dengan hijaiyah yang tampil

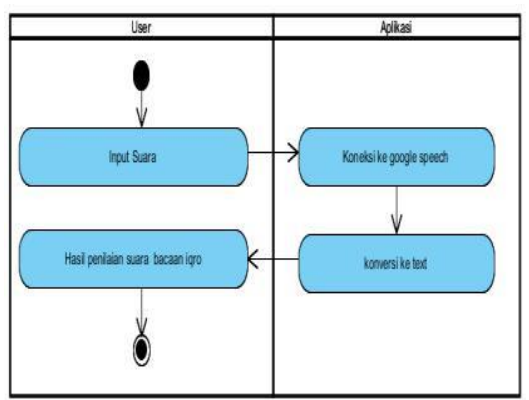

Gambar 4. Activity diagramInput Suara

digunakan untuk memasukkan suara sesuai dengan bacaan hijaiyah yang tampil di layar. Sistem mengkoneksikan ke google speech setiap suara yang masuk, lalu dikonversi menjadi text. Text inilah yang menjadi tolak ukur pencocokan apakah sesuai dengan directory, jika sesuai maka mendapatkan poin penuh

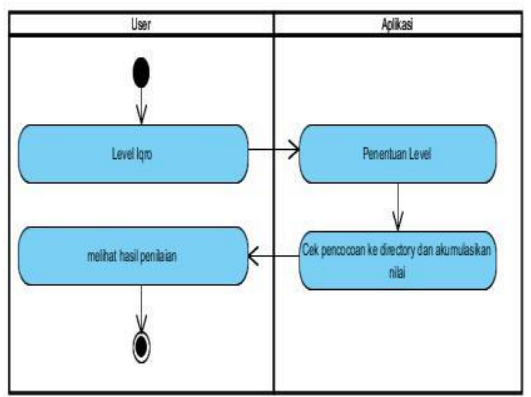

Gambar 5. Activity diagram level iqro

pada menu level digunakan untuk melihat hasil penilaian sesuai dengan tingkat keberhasilan user dalam memasukkan suara berdasarkan hijaiyah yang ditampilkan di layar.

\section{Sequensial Diagram}

Diagram sequence (urutan) adalah diagram interaksi yang menekankan pada pengiriman pesan (message) dalam suatu waktu tertentu.

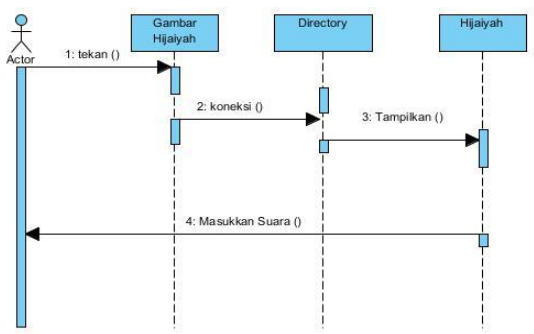

Gambar 6.Sequence DiagramGambar Hijaiyah 
user menekan tombol gambar hijaiyah.

Reaksi aplikasi menyiapkan content gambar hijaiyah. Selanjutnya user dapat memasukkan suara sesuai dengan hijaiyah yang tampil

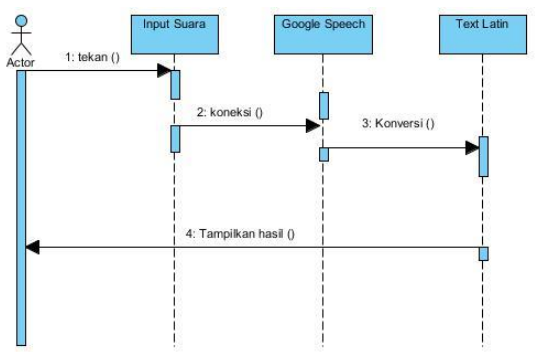

Gambar 7.Sequence Diagram Menu Reliks

digunakan untuk memasukkan suara sesuai dengan bacaan hijaiyah yang tampil di layar. Sistem mengkoneksikan ke google speech setiap suara yang masuk, lalu dikonversi menjadi text.Text inilah yang menjadi tolak ukur pencocokan apakah sesuai dengan directory, jika sesuai maka mendapatkan poin penuh.

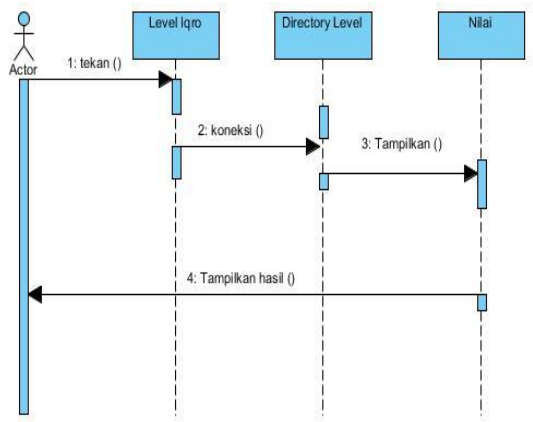

Gambar 8.Sequence DiagramMenu Multimedia

pada menu level digunakan untuk melihat hasil penilaian sesuai dengan tingkat keberhasilan user dalam memasukkan suara berdasarkan hijaiyah yang ditampilkan di layar.

E. Storyboard

Langkah selanjutnya adalah perancangan storyboard.Tahap ini sangat membantu dalam menyusun frame by frame pembuatan game.
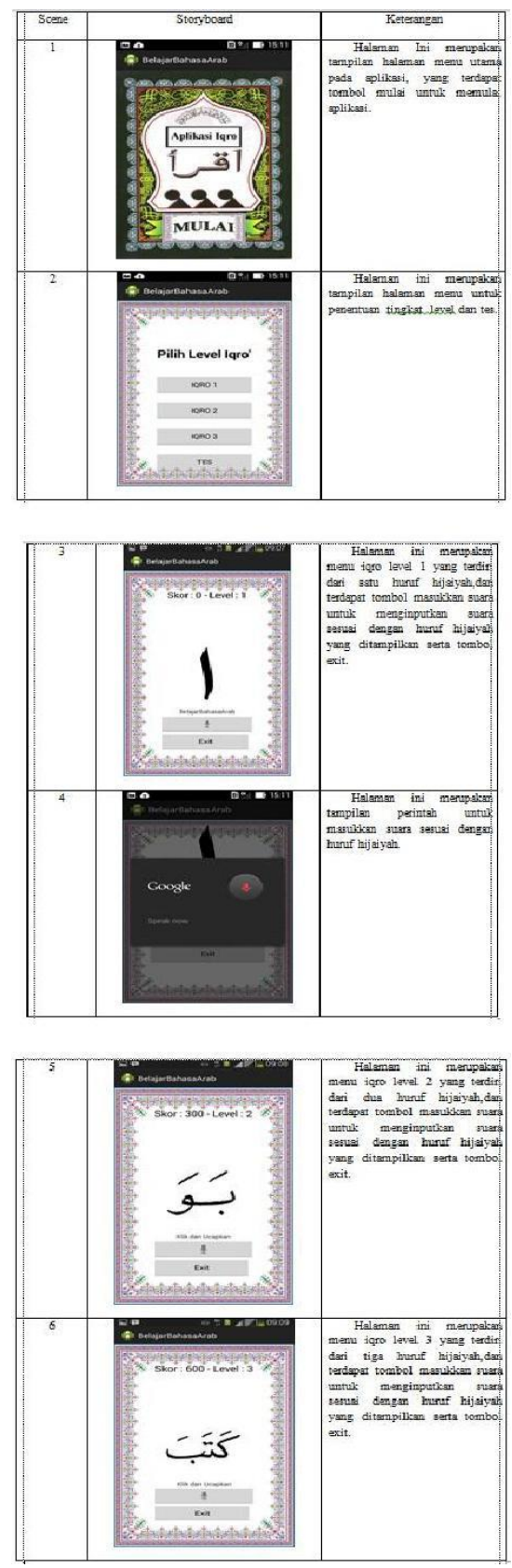

Gambar 9. Storyboard

\section{IMPLEMENTASI}

\section{A. Hasil implementasi Program}

Pada implementasi penentuan level pembelajaran iqro' pada program aplikasi dilakukan dengan menggunakan bahasa pemrograman java eclipse berbasis Android. Berikut hasil implementasi program menu utama seperti pada Gambar 11. 


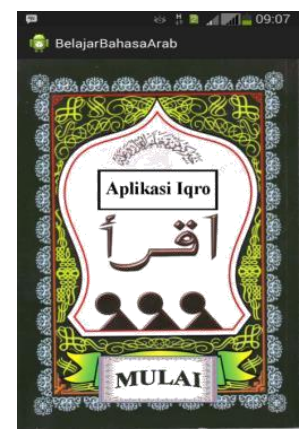

Gambar 11. Menu Utama Iqro'

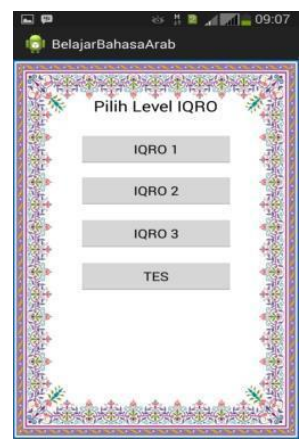

Gambar 12. Menu pilihan aplikasi

Pada Gambar 4.2, terdapat 4 menu pilihan diantaranya iqro 1, 2, 3 dan tes. Menu iqro 1 terdiri dari 1 huruf hijaiyah seperti dalam Gambar 4.3

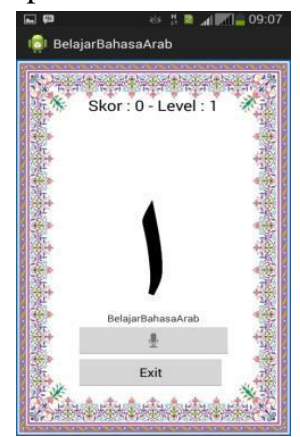

Gambar 13. Menu pilihan aplikasi iqro' 1

Sedangkan iqro 2 terdiri dari 2 huruf hijaiyah seperti pada Gambar 4.4

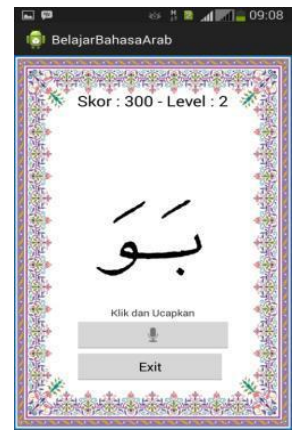

Gambar 14. Menu pilhan aplikasi iqra' 2
Untuk aplikasi iqro 3 terdiri dari 3 huruf hijaiyah, menu iqro 1,2 dan 3 digunakan jika pengguna sudah fasih iqro 1 maka dapat memilih iqro sesuai dengan kemampuannya. Setiap huruf hijaiyah yang berhasil dijawab dengan benar mendapatkan nilai 100. Apabila salah tetap pada hijaiyah yang diucapkan salah. Menu iqro 3 seperti pada Gambar 4.5

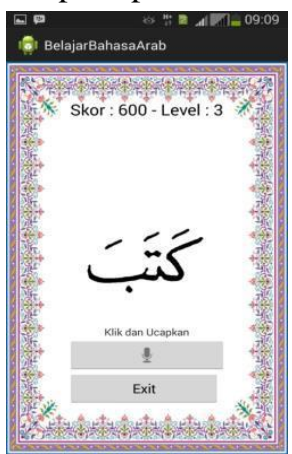

Gambar 15. Menu Pilihan Aplikasi Iqro 3

Pada penelitian ini disajikan menu tes yang berfungsi untuk mengevaluasi peserta sejauh mana tingkat keberhasilannya dalam memahami huruf hijaiyah. Setiap menekan menu tes, peserta disajikan beberapa huruf hijaiyah. Menu ini meskipun pengguna salah mengucapkan hijaiyah sesuai dengan gambar tetap dapat melanjutkan ke hijaiyah selanjutnya dan aplikasi mengakumulasikan nilai yang berhasil dijawab dengan benar dan salah. Kesalahan dalam mengucapkan huruf hijaiyah mengakibatkan pengguna harus mengulang sampai berhasil dengan menekan tombol tes seperti pada Gambar 16.

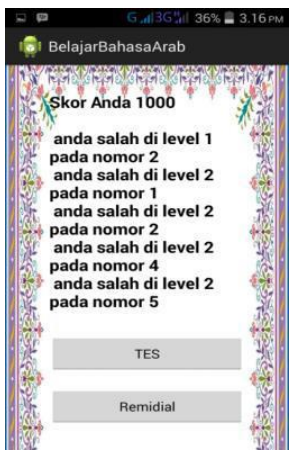

Gambar 16. Akumulasi hasil tes iqro'

\section{B. Dokumentasi Hasil Ujicoba Program}

Uji coba ini dilakukan guna mendapatkan kesesuain kerja system dan untuk mengetahui kekurangan system. 


\section{Pengujian Level Iqro’ (Huruf Hijaiyah)}

Uji coba ini dilakukan guna mendapatkan kesesuain kerja system dan untuk mengetahui kekurangan system.

Proses pengujian ini dilakukan untuk mengetahui seberapa benar atau fasih dalam pengucapan huruf hijaiyah yang telah ditampilkan.misalnya,huruf “ dibaca "Bak"),ketika waktu memasukkan suara, user mengucapkan "Bhak"(ngebass),maka system secara otomatis tidak membenarkan pengucapannya dan user tidak bisa melanjutkan ke huruf selanjutnya serta tidak mendapatkan skor.

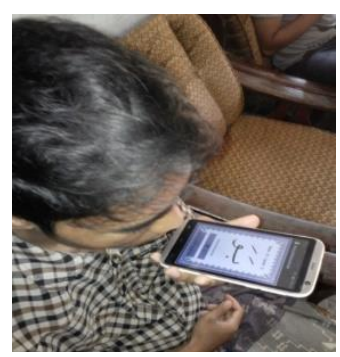

Gambar 17. Uji coba level iqro'

Jarak Memasukkan Suara Ke Smartphone

Proses pengujian ini dilakukan untuk mengetahui kepekaan system terhadap suara yang kita masukkan.jarak yang ideal untuk memasukkan suara 3 $\mathrm{cm}$ dari mulut ke smartphone.

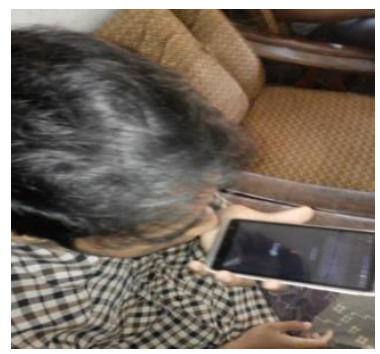

Gambar 18. Uji coba memasukkan suara/voice

\section{KESIMPULAN DAN SARAN}

A. Kesimpulan \& Saran

Dari penelitian yang telah dilakukan, maka diperoleh kesimpulan,diantaranya :

- Aplikasi bisa dipakai untuk belajar iqra' dengan metode input suara/voice

- $\quad$ Berdasarkan hasil pengujian, program sangat membantu peserta yang ingin belajar iqro dan dapat mengukur kemampuan individu sejauh mana peserta tersebut memahami huruf hijaiyah

Adapun saran untuk penelitian selanjutnya dapat ditambahkan:

- Penelitian ini dapat dikembangkan ke metode yang lain, misalkan Linear Predictive Coding

- Gunakan sistem offline supaya tidak tergantung pada internet

- Tambahkan sistem gain untuk membantu pengambilan suara dari jarak yang lebih jauh dengan microphonehandphone

\section{REFERENSI}

[1] Arsyad, Azhar. 2004. Media Pembelajaran. Jakarta : PT. Raja Grafindo Persada

[2] Begam, M. Muda, L dan Elamvazuthi, L. 2010. Voice Recognition Algorithms using Mel Frequency Cepstral Coefficient (MFCC) and Dynamic Time Warping (DTW) Techniques. Journal Of Computing, Volume 2, Issue 3, March 2010, ISSN 2151-9617

[3] Hapsari, J, Putri. 2008. Aplikasi Pengenalan Pola Suara dalam Pengaksesan Sistem Informasi Akademik. Universitas Diponegoro Semarang

[4] Ichwan, M dan Hakiky, Fifin.2011.Pengukuran Kinerja Goodreads Application Programming Interface (API) Pada Aplikasi Mobile Android. Jurnal Informatika No.2 , Vol. 2, Mei - Agustus 2011

[5] Latief, Nurul M. 2013. Training Monitoring System for Cyclist Based on Android Application Development. Department of Communication Engineering, Faculty of Electrical Engineering, Universiti Teknologi Malaysia

[6] Lovindha, O. 2015.Sistem Pendukung Keputusan Rekomendasi Pemilihan dan Pemesanan Tempat Wisata Menggunakan Metode Fuzzy Sugeno (Studi Kasus CV Pritama Tours Tujuan Wisata Yogyakarta). Universitas Muhammadiyah. Malang.

[7] Munawar. 2005. Permodelan visual dengan UML. Graha Ilmu. Yogyakarta

[8] Nazruddin, Safaat H. 2012. Pemrograman Aplikasi Mobile Smartphone dan Tablet PC Berbasis Android. Informatika

[9] Pan, Shing-Thai.Lai, Chin-Chin dan Tsai, Bo-Yu. 2011. The Implementation Of Speech Recognition Systems on FPGA-Based Embedded Systems With SOC Architecture. International Journal of Innovative Computing, Information and Control Volume 7, Number 11, November 2011

Unikom, 2016.Use Case Skenario. Universitas Komputer Indonesia.Bandung

[11] Zuliana,Choliz.2007.AplikasiMultimedia

Pembelajaran Iqro’ Sebagai Sarana Mempelajari Huruf Al-Quran. Fakultas Matematika dan Ilmu Pengetahuan : Universitas Sebelas Maret. Surakarta 